\title{
Improvement rates in adolescent patients with chronic fatigue syndrome after receiving cognitive behavioural therapy
}

\author{
Robert Courtney
}

Received: 19 October 2013 / Accepted: 28 November 2013 / Published online: 10 December 2013

(C) Springer-Verlag Berlin Heidelberg 2013

Werker et al. [7] claim that several randomised controlled trials have demonstrated that cognitive-behavioural therapy (CBT) resulted in improvement and 'recovery' in 60-70\% of adolescent patients with chronic fatigue syndrome when assessed at 6 months $[3,4,6]$, with 'comparable results at 23-year follow-up' $[2,5]$.

However, I believe further data from the cited research studies would have been helpful to put the results in their full context.

The open-label FITNET trial $[4,5]$ did indeed report a $63 \%$ 'recovery' rate at 6 months. However, the trial used a post hoc definition of 'recovery' which has been criticised for not being stringent enough $[1,8]$. Furthermore, the follow-up paper concluded that receiving CBT 'did not significantly influence recovery rates' at long-term follow-up (LTFU), as there was no significant difference between CBT and the 'usual care' control group.

In another cited study, Stulemeijer et al. compared CBT to a waiting list control. The proportion of patients who improved in fatigue and physical function was reported as 60 and $63 \%$, but when compared to the control group, the additional proportion of patients who improved after CBT was as follows: fatigue severity $39 \%$; physical functioning $39 \%$; full school attendance $29 \%$; and self-rated improvement $27 \%$ [6].

Knoop et al. reported improvement rates of 60-74\%, but when compared to a waiting list control, the improvement rates for CBT at LTFU were $33 \%$ for fatigue, and $24 \%$ for physical functioning, with similar rates at immediate assessment [2].

This paper is a letter in response to: Werker CL, Nijhof SL, van de Putte EM (2013) Clinical Practice: Chronic fatigue syndrome. Eur J Pediatr 172(10):1293-1298.

R. Courtney $(\bowtie)$

London, United Kingdom

e-mail: information785@gmail.com
The remaining cited study, by Lim and Lubitz, investigated an intensive multi disciplinary inpatient rehabilitation programme. Improvement rates were not presented in comparison to the control group, and $68 \%$ of participants reported that they felt the psychological component of the programme was unhelpful or that they felt indifferent towards it [3].

Conflicts of interest None.

\section{References}

1. Kindlon T (2012) Internet-based CBT for adolescents with chronic fatigue syndrome. Lancet 380(9841):561

2. Knoop H, Stulemeijer M, de Jong LW, Fiselier TJ, Bleijenberg G (2008) Efficacy of cognitive behavioral therapy for adolescents with chronic fatigue syndrome: long-term follow-up of a randomized, controlled trial. Pediatrics 121(3):e619-e625

3. Lim A, Lubitz L (2002) Chronic fatigue syndrome: successful outcome of an intensive inpatient programme. J Paediatr Child Health 38(3):295-299

4. Nijhof SL, Bleijenberg G, Uiterwaal CS, Kimpen JL, van de Putte EM (2012) Effectiveness of internet-based cognitive behavioural treatment for adolescents with chronic fatigue syndrome (FITNET): a randomised controlled trial. Lancet 379(9824):1412-1418

5. Nijhof SL, Priesterbach LP, Uiterwaal CS, Bleijenberg G, Kimpen JL, van de Putte EM (2013) Internet-based therapy for adolescents with chronic fatigue syndrome: long-term follow-up. Pediatrics 131(6): e1788-e1795

6. Stulemeijer M, de Jong LW, Fiselier TJ, Hoogveld SW, Bleijenberg G (2005) Cognitive behaviour therapy for adolescents with chronic fatigue syndrome: randomised controlled trial. BMJ 330(7481):14

7. Werker CL, Nijhof SL, van de Putte EM (2013) Clinical practice: chronic fatigue syndrome. Eur J Pediatr 172(10):1293-1298

8. White PD, Chalder T (2012) Chronic fatigue syndrome: treatment without a cause. Lancet 379(9824):1372-1373 